\title{
Growth and Flowering of Zantedeschia elliottiana and $Z$. rehmannii in Response to Environmental Factors
}

\author{
Brian E. Corr ${ }^{1}$ and Richard E. Widmer ${ }^{2}$ \\ Department of Horticultural Science, University of Minnesota, St. Paul, \\ MN 55108
}

Additional index words. calla lily, floriculture, flowering potted plants, leaf area,
irradiance level, photoperiod, medium and air temperature

Abstract. The influences of irradiance level, day length, temperature, and leaf area on growth and flowering of Zantedeschia elliottiana Engl. W. Wats (yellow calla lily) and $Z$. rehmannii (pink calla lily) were determined. Plants grown with $45 \%$ or $15 \%$ of natural irradiance were taller than those grown under full natural irradiance but flowered at the same time and produced a similar number of flowers. Leaf removal treatments had no effect on any characteristic measured. Plants grown with a night interruption (NI; $2200 \mathrm{HR}$ to $0200 \mathrm{HR}$ ) were taller than those under short days (SD = 8 hours), but flowered at the same time and produced a similar number of flowers. Plants were grown with air at 15 or $20 \mathrm{C}$ in combination with medium temperatures at ambient level (1C less than air temperature) or a constant 20 or $25 \mathrm{C}$. $Z$. rehmannii grown with the medium at 20 or $25 \mathrm{C}$ and air at 1.5 or $20 \mathrm{C}$ flowered faster and were taller than plants grown with air at $15 \mathrm{C}$ and with the medium at ambient temperature, but plants from all temperatures produced the same number of flowers over a 120-day cycle. When plants grown with a NI in the first cycle were replanted and grown through a second cycle, they were taller than plants grown from SD treatment first-cycle plants. No first growth-cycle treatment influenced flowering in the second growth cycle.

Yellow and pink callas are grown for flowering potted plants and cut flowers (Ball, 1986). Foliage of these species senesces in response to periodic drought in their native habitat (Letty, 1973). In the United States, Zantedeschia rhizomes are produced in fields in California, with irrigation discontinued before harvest to induce foliar senescence. Initiation of Zantedeschia flowers occurs shortly after replanting rhizome that have been harvested from California fields (Corr, 1988). We found no studies on environmental factors controlling flower initiation and development.

Flowering of some genera in the Araceae is partially controlled by irradiance levels. The effect of reduction of photosynthesis, either by removal of leaves or by shading, has been studied in Anthurium. Decreased irradiance lowered the number of flowers per plant and increased flower stem length

Received for publication 3 Apr. 1989. Scientific Journal Series Paper 16,932, Minnesota Agricultural Experiment Station, Univ. of Minnesota, St Paul, MN 5.5108. We thank Golden State Bulb Growers, Capitola, Calif., for donating the rhizomes used in this study. Portions of this research were funded by a grant from the American Floral Endowment. The cost of publishing this paper was defrayed in part by the payment of page charges. Under postal regulations, this paper therefore must be hereby marked advertisement solely to indicate this fact.

'Graduate student. Present address: Dept. of Ornamental Horticulture and Landscape Design, Univ. of Tennessee, P.O. Box 1071, Knoxville, TN 37901.

${ }^{2}$ Professor Emeritus. number of flowers of Xanthosoma (also Araceae) were the same under 8-hr days and 8$\mathrm{hr}$ days with an incandescent light extension to $18 \mathrm{hr}$, but petiole elongation was greater under day extension compared to 8-hr daylength (McDavid and Alamu, 1979). Floral development of Lilium longiflorum was unaffected by daylength, but plants were taller under long than short days (Heins et al., 1982).

Zantedeschia elliottiana grown at 21C flowered 17 days earlier than plants grown at $15 \mathrm{C}$. Rhizomes grown at $10 \mathrm{C}$ did not sprout until greenhouse temperatures naturally increased above 15C. Plant height and number of flowers were not reported (Post, 1936). Flowering of other Araceae is affected by temperature. Anthurium schenetiunum grown at $15 \mathrm{C}$ produced 112 flowers, while plants at $21 \mathrm{C}$ produced only 50 flowers during 70 days (Noordegraaf, 1973). Over a 240-day growing period $A$. schenetianum produced $210,180,120$, and 110 flowers at 15, 20, 25 , and 10C, respectively (Maatsch and Bachthaler, 1964). Transferring A. scherzerianum plants from 21 to $9,12,15$, or $18 \mathrm{C}$ for 4,6 , or 8 weeks before returning the plants to $21 \mathrm{C}$ increased flower production compared to plants grown continually at $21 \mathrm{C}$ (Noordegraaf, 1973).

We found no report in the literature of the effect of medium temperature on Zantedeschia growth or development. Air and medium temperatures have been shown to influence the growth of Dieffenbachia maculata, another member of the Araceae. With air at $18.5 \mathrm{C}$, plants were taller in medium held at $18.5 \mathrm{C}$ than in one at $13 \mathrm{C}$ and taller at 24 than at $29.5 \mathrm{C}$. In $13 \mathrm{C}$ air, height increased approximately linearly with increasing medium temperature (Conover and Poole, 1987). Significant medium temperature effects on many plant characteristics have been found in several species (Cooper, 1973). Petunia hybrida grown at an elevated medium temperature had a larger leaf area, were taller, and bloomed sooner than those at lower temperatures (Merritt and Kohl, 1982).

Our experiments were designed to determine the effects of irradiance level, leaf area, temperature, and photoperiod on flower development during the first growth cycle fol-

Table 1. Effect of photoperiod on plant height and peduncle length of Zantedeschia elliottiana and Z. rehmannii.

\begin{tabular}{|c|c|c|c|c|}
\hline \multirow[b]{2}{*}{ Photoperiod $^{z}$} & \multirow{2}{*}{$\begin{array}{c}\text { Plant ht at } \\
\text { first flower }(\mathrm{cm})\end{array}$} & \multicolumn{2}{|c|}{ Plant ht $(\mathrm{cm})$} & \multirow{2}{*}{$\begin{array}{l}\text { Peduncle length } \\
(\mathrm{cm})\end{array}$} \\
\hline & & 60 days & 90 days & \\
\hline \multicolumn{5}{|c|}{ Z. elliottiana } \\
\hline $\mathrm{SD}$ & 41.8 & 38.0 & 43.3 & 40.0 \\
\hline NI & 58.5 & 52.7 & 63.3 & 49.2 \\
\hline $\mathrm{HSD}_{0.05}$ & 7.0 & 5.1 & 8.8 & 8.7 \\
\hline $\mathrm{HSD}_{0.01}$ & 9.8 & 7.2 & 12.3 & 12.1 \\
\hline \multicolumn{5}{|c|}{ Z. rehmannii } \\
\hline SD & 38.5 & 36.7 & 39.2 & 19.7 \\
\hline NI & 57.0 & 54.4 & 62.6 & 38.4 \\
\hline $\mathrm{HSD}_{0.05}$ & 4.4 & 3.2 & 2.6 & 4.3 \\
\hline $\mathrm{HSD}_{0,01}$ & 6.1 & 4.4 & 3.6 & 5.9 \\
\hline
\end{tabular}

${ }^{2} \mathrm{SD}=$ plants covered with light-excluding woven black plastic from $1600 \mathrm{HR}$ to $0800 \mathrm{HR}$. NI = plants covered with light-excluding woven black plastic from $1600 \mathrm{HR}$ to $0800 \mathrm{HR}$ but irradiated from 2200 $\mathrm{HR}$ to $0200 \mathrm{HR}$. 


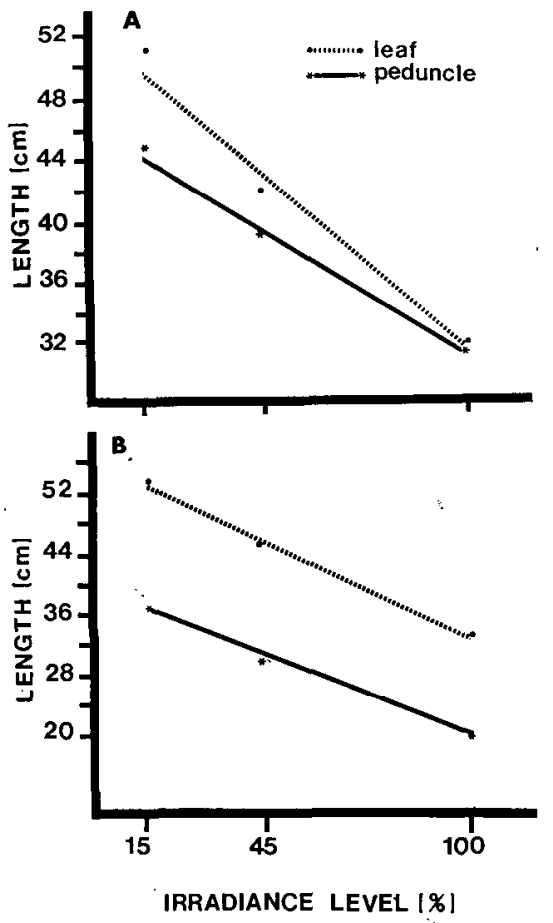

Fig. 1. Effect of irradiance on leaf and peduncle length of Zantedeschia elliottiana (A) and $Z$. rehmannii (B). Z. elliottiana leaf length: $\mathrm{Y}=$ $53.06-0.210 \mathrm{X}, R^{2}=0.80, P<0.001$; peduncle length: $\mathrm{Y}=51.85-6.42 \mathrm{X}, R^{2}=$ $0.61, P=0.004 . Z$. rehmannii leaf length: $\mathrm{Y}$ $=56.76-0.24 \mathrm{X}, R^{2}=0.86, P<0.001$; peduncle length $\mathrm{Y}=39.716-0.20 \mathrm{X}, R^{2}=$ $0.82, P<0.001$.

lowing harvest from the field. Flowering in the next cycle of growth following foliar senescence and rhizome harvest was also studied.

Zantedeschia elliottiann and Z. rehmannii rhizomes were received from California in late Feb. 1986. After storage at 20C, rhizomes were planted 10 June in a 1 sphagnum peat : 1 perlite: 1 loam soil (by volume) mix in $15 \mathrm{~cm}$ (1.15 liter) plastic pots and grown in a glasshouse as previously described (Corr and Widmer, 1987), unless otherwise noted. To investigate the effect of leaf removal on flower development, an entire leaf blade was removed at the juncture of blade and petiole, or one-half of the blade was removed by slicing through the blade adjacent to the midrib from blade base to tip with a razor blade. The first, second, or third leaf of each shoot was selected as it unfolded. In a separate experiment, rhizomes were planted on 10 June as previously described, then grown under full available irradiance or one or two layers of Saran shading material $(1220,550$, or 170 umol $\cdot \mathrm{s}^{-1} \cdot \mathrm{m}^{-2}$ respectively, on a cloudless day at midday).

Rhizomes of Z. elliottiana and Z. rehmannii were received from California on 4 Feb. 1987 and planted the following day as described previously. Plants were grown in a glasshouse held at a minimum of $20 \mathrm{C}$, increasing up to $25 \mathrm{C}$ on sunny days. For photoperiodic control, a woven black plastic

Table 2. Effect of photoperiod during the first or second growth cycle on height of $Z$. rehmannii during the second growth cycle.

\begin{tabular}{cccccc}
\hline \multirow{2}{*}{$\begin{array}{c}\text { Photoperiod } \\
\text { growth cycle }\end{array}$} & & \multicolumn{4}{c}{ Days post-plant } \\
\cline { 4 - 7 } & Second & & \multicolumn{4}{c}{ Plant ht (cm) } \\
\cline { 4 - 7 } First & NI & 45.8 & 40 & 80 & 100 \\
\hline SD & SD & 34.0 & 37.0 & 54.6 & 59.6 \\
SD & SD & 45.2 & 47.4 & 38.6 & 39.8 \\
NI & NI & 54.0 & 56.5 & 49.2 & 50.8 \\
NI & & 5.7 & 5.5 & 59.2 & 63.0 \\
HSD $_{0.05}$ & & 7.4 & 7.0 & 5.2 & 4.7 \\
HSD $_{0.01}$ & & & 6.7 & 6.0 \\
\hline
\end{tabular}

${ }^{\mathrm{z}} \mathrm{SD}=$ plants covered with light-excluding woven black plastic from $1600 \mathrm{HR}$ to $0800 \mathrm{HR} ; \mathrm{NI}=$ plants covered with light-excluding woven black plastic from $1600 \mathrm{HR}$ to $0800 \mathrm{HR}$ and irradiated from 2200 $\mathrm{HR}$ to $0200 \mathrm{HR}$.

Table 3. The effect of medium and air temperature on development of Zantedeschia rehmannii.

\begin{tabular}{ccccc}
\hline \hline \multicolumn{2}{c}{ Temperature $\left({ }^{\circ} \mathrm{C}\right)$} & $\begin{array}{c}\text { Days to } \\
\text { first flower }\end{array}$ & $\begin{array}{c}\text { Ht at first } \\
\text { flower }(\mathrm{cm})\end{array}$ & $\begin{array}{c}\text { Peduncle } \\
\text { length }(\mathrm{cm})\end{array}$ \\
\hline Air & Medium $^{2}$ & 85.2 & 37.6 & 22.6 \\
15 & am & 70.6 & 40.2 & 27.4 \\
15 & 20 & 68.2 & 39.6 & 27.2 \\
15 & 25 & 67.4 & 46.2 & 28.8 \\
20 & am & 62.0 & 48.6 & 33.0 \\
20 & 25 & 13.4 & 9.3 & 9.4 \\
HSD $_{0.05}$ & & 16.8 & 11.7 & 11.7 \\
HSD $_{0.01}$ & & & \\
\hline
\end{tabular}

$\mathrm{z}_{\mathrm{am}}=$ ambient temperature, which averaged $1 \mathrm{C}$ below air temperature.

cover with reflective white exterior was drawn over all the plants from $1600 \mathrm{HR}$ to $0800 \mathrm{HR}$ daily to exclude light. A divider that excluded light separated the plants into two treatments. Short-day treatment (SD) received no light between 1600 HR and 0800 HR. Night interruption plants (NI) were irradiated from 2200 HR to 0200 HR by coolwhite fluorescent lamps filtered with orange and red cellophane to exclude most photosynthetically active radiation $(<10$ umol $\left.\cdot \mathrm{s}^{-1} \cdot \mathrm{m}^{-2}\right)$. The ratio of red $(660 \mathrm{~nm})$ to far-red (730 mn) light was 8:1.

Starting 100 days after planting, irrigation was withheld to induce foliar senescence, and rhizomes were harvested 1 month later. Rhizomes were then stored at $15 \mathrm{C}$ for 6 weeks to promote vegetative growth after replanting (Corr and Widmer, 1988). Z. rehmannii rhizomes were replanted, with half of the rhizomes from each first growth cycle photoperiod treatment grown under SD and the other half under NI. Z. elliottiana rhizomes were discarded due to severe infection with Erwinia soft rot.

Rhizomes of Z. elliottiana and Z. rehmanni were received from a California producer on 4 Feb. 1987, planted the following day as described previously, and placed at five air/medium temperature combinations: $15 \mathrm{C}$ air with ambient, 20 , or $25 \mathrm{C}$ medium temperature; and $20 \mathrm{C}$ air with ambient or 25C medium temperature. Ambient medium temperatures were $\approx 1 \mathrm{C}$ lower than those of the air. To maintain constant medium temperatures, pots were placed on a $2.5-\mathrm{cm}$ layer of sand over electric heating cables that were placed on galvanized screen resting on polystyrene foam sheets. All pots within a given temperature treatment were enclosed on all sides in polystyrene foam to help retain bot- tom heat and maintain uniform temperatures within treatments.

Irrigation was withheld beginning 115 days after planting to induce foliar senescence. Rhizomes were harvested 1 month later, then stored for 6 weeks as described by Corr and Widmer (1988). Rhizomes were replanted (12 Aug.) and grown at ambient photoperiod with 20C minimum temperature.

Rhizomes were graded to ensure similar sizes in all treatments in an experiment. All experiments were designed and analyzed as completely randomized designs, with five replicates per treatment. Each replicate consisted of a single plant.

Leaves and peduncles (stalks supporting the spathe and spadix) were longer on plants grown under reduced irradiance than on plants under full available irradiance (Fig. 1). There was no significant effect of reduced irradiante on date of first flower, total number of flowers, or spathe length or width in either species. None of the leaf removal treatments had a significant effect on any of the factors measured: number of developed shoots, number of leaves expanded before first flower, peduncle length, leaf length, days from emergence to first flower, date of first flower, or total number of flowers.

Plants grown under NI were significantly taller at first flower and at 60 and 90 days post-planting, with longer peduncles than plants grown under SD (Table 1). Photoperiod had no significant effect on the number of leaves, shoots, or flowers at 60 or 90 days post-planting, number of leaves before first flower, date of first flower, or total number of flowers in the first growth cycle (data not shown).

Plants were significantly taller during a second growth cycle if-grown with a NI in 
either the first or second growth cycle than those grown under SD (Table 2). Photoperiod during the first or second growth cycle had no effect on days to emergence, number of leaves, number of shoots, days to first flower, number of leaves before the first flower, or total number of flowers in 120 days of the second growth cycle (data not shown).

Z. rehmannii grown at the higher medium or air temperatures flowered sooner and were taller with longer peduncles than those grown at lower temperatures (Table 3). There was no signifidant effect of temperature on any characteristic of $Z$. elliottiana growth or on the number of flowers produced by either species over 115 days.

There was no effect of air or medium temperatures during the first growth cycle on plant height or days to emergence of either species in the second growth cycle. There was no effect of air or medium temperature during the first cycle of $Z$. elliottiana growth on days to first flower or number of flowers produced during the second growth cycle. No Z. rehmannii plants flowered in 120 days after planting in the second growth cycle.

The lack of any effect of either leaf removal or decreased irradiance on number of flowers produced or days to first flower supports the conclusion that inflorescence development is not dependent on current photosynthate within the ranges of these experiments. Leaf and peduncle length were longer under low irradiance, which is similar to the response of Anthurium (Nakesone and Kamemoto, 1962).

There is no evidence for a photoperiodic effect on flower initiation or development, although peduncle length and plant height were significantly affected. This is similar to the sesponse of Xanthosoma, which also was unaffected by photoperiod for all factors measured except petiole elongation (McDavid and Alamu, 1979). No reference to a carryover effect of photoperiod on any factor in the second growth cycle was found in the literature.

Plants flowered sooner and were taller at $20 \mathrm{C}$ air than at $15 \mathrm{C}$ air (Table 3). By heating the medium to $20 \mathrm{C}$, time to flower in $15 \mathrm{C}$ air was approximately equivalent to that for air at 20C (Table 3). The lower air temperature with heated medium may be a more economical glasshouse environment for crop production than a higher air temperature with ambient medium temperature.

The increase in plant height at low irradiance, with night interruption, or at higher medium temperatures may result in unacceptably tall plants for flowering potted-plant production. If necessary, height control of Zantedeschia may be achieved with an application of paclobutrazol (Tjia, 1987).

None of the environmental treatments of the first growth cycle influenced flowering in the second growth cycle. Therefore, the environmental control of floral initiation, if any, remains unknown.

\section{Literature Cited}

Ball, V. 1986. A promising new pot plant. Grower Talks Nov. 1986. p. 48-51.

Conover, CA. and R.T. Poole. 1987. Growth of Dieffenbachia maculata 'Perfection' as affected by air and soil temperatures and fertilization.HortScience 22:893-895.

Cooper, A.J. 1973. Root temperature and plant growth. Cmwlth. Bur. Hort. Crops, E. Malling, Res. Rev. 4:1-73.

Con, B.E. 1988. Factors influencing growth and flowering of Zantedeschia elliottiana and $Z$. rehmannii. PhD Thesis, Univ. of Minnesota, St. Paul.

Corr, B.E. and R.E. Widmer 1987. Gibberellic acid increases flower number in Zantedeschia elliottiana and Z. rehmannii. HortScience 22:605-607.

Corr, B.E. and R.E. Widmer. 1988. Rhizome storage increases growth of Zantedeschia elliottiana and Z. rehmannii. HortScience 23:1001-1002.

Ghani, F.D. 1984. Preliminary studies on flowering in taro cultivars in Malaysia, p. 169-172. In: S. Chandra (ed.). Edible aroids. Oxford University Press, London.

Greene, L., R.B. Withrow, and M.W. Richman. 1932. The response of greenhouse crops to electric light supplementing daylight. Ind. Agr. Expt. Sta. Bul. 366.

Heins, R.D., H.F. Wilkins, and W.E. Healy. 1982. The influence of light on lily (Lilium longiflorum Thunb.). II. Influence of photoperiod and light stress on flower number, height and growth rate. J. Amer. Soc. Hort. Sci. 107:335-338.

Letty, C. 1973. The genus Zantedeschia. Bothalia 11,1 and 2:5-26.

Maatsch, R. and E. Bachthaler. 1964. Einfluss verschiedener nachttemperaturen auf die Bildung and Entwicklung der Blutenstande bei Anthurium scherzerianum hort. Gartenwelt 64:273274.

McDavid, C.R. and S. Alamu. 1979. Effect of daylength and gibberellic acid on the growth and promotion of flowering in tannia (Xanthosoma sagittifolium). Trap. Agr. 56:17-23.

Merritt, R.H. and H.C. Kohl. 1982. Effect of root temperature and photoperiod on growth and crop efficiencyof Petunia. J. Amer. Soc. Hort. Sci. 107:997-1000.

Nakesone, H.Y. and H. Kamemoto. 1962. Anthurium culture. Hawaii Agr. Expt. Sta. Tech. Bul. 50.

Noordegraaf, C.V. 1973. Influence of temperature on flowering in Anthurium schenerianum. Acta Hart. 31:71-76.

Post, K. 1936. Further responses of miscellaneous plants to temperature. Proc. Amer. Soc. Hort. Sci. 34:3627-629.

Tjia, B. 1987. Growth regulator effect on growth and flowering of Zantedeschia rehmannii hyb. HortScience 22:507-8. 